\title{
Publication ethics standards in Geoinformatics FCE CTU
}

\author{
Editorial
}

Dear Readers,

In our previous editorial (No. 1/2015), we have introduced the basic technological publishing standards. Now it is time to follow up and introduce also ethical issues related to scholarly publishing.

Open Access, Open publishing, and Open scientific environment bring great opportunities as well as unfortunately higher threads in scholarly publishing. The open electronic environment accelerates the information and publishing process and the quantity of information being communicated, however the authors, reviewers and readers are still human beings, and the day still has 24 hours.

The technology is quite not that far at all to be able to check human motivation, thoughts, honesty, and righteousness. Every possible technical attempt to check the quality of any work, article, journal, review is short when it comes down to human invention. Thus, in order to keep high quality in scholarly communication, the worldwide academic community together with the prestigious international scholarly publishers have defined a set of ethical principles in scholarly publishing. These principles are not meant to constrain authors or other parties in their rights in free scholarly publishing. It is meant to prevent fraud that cheats mostly and above all the end readers.

An associated issue related not only to publication ethics is worth mentioning as well. People keep inventing many principles focused on preventing negative aspects - constraints, criticism, punishments, pursuing negative aspects of human behavior. Positive motivation is rare. Perhaps an opposite attitude might be considered - to focus on the honest and righteous researchers, to establish a set of positive criteria to reward and motivate those researchers by positive means rather than frightening them with restrictions. Is there a place to focus on prevention in the positive manner rather than on punishing negative behavior? Especially since many negative aspects might be generated also by lack of experience, not only by purposeful cheating. This is a broad issue which should have an entirely individual article devoted to, however we believe it should have been at least mentioned together with this topic as well. Now, back to the reality of ethical standards and criteria of ethical scholarly publishing.

Many journal editors accept their own ethical standards and publication ethic statements. Many of those are members or just follow ethical guidelines and other activities conducted by organizations that focus on keeping ethical principles with research and publishing activities. There are numerous organizations that publish publication ethics statements, e.g. COPE (Committee on Publication Ethics), a British membership organization open to all editors of academic journals and anyone who is interested in publication ethics. It provides advices in all aspects of publication ethics, guidelines, samples, and above all it provides help to all its members with any ethics violation cases. Besides COPE, there are further numerous organizations dealing with research and publication ethics guidance and advisement, most of them focused on a particular research area, e.g. Medicine, etc.

Geoinformatics FCE CTU 15(1), 2016, doi:10.14311/gi.15.1.0 
COPE clearly defines the ethical principles that are expected from the authors, reviewers, editors, and the publisher that are acceptable in all research areas. These principles have been adopted by Geoinformatics FCE CTU Journal.

Most publishers strive to publish original content which brings new findings in the particular research field. Authors shall thus submit only original work, which has not been plagiarized and has not been published anywhere else nor has been submitted to other publication simultaneously. Authors should list only the real contributors to the work, and should not forget or omit any team member who has been responsible for the work. Guest, gift, and ghost authorship are prohibited. All co-authors take collective responsibility for their work and for the content of their publications.

Authors shall present only complete and final research results. Research presented in the publication should have been conducted in ethical manner, research results shall be presented honestly, without falsifications, or any inappropriate data manipulation, i.e. methods used, calculations, findings, and data presentation shall be checked carefully to make sure all information at all stages is correct. All research stages shall be described clearly to allow other research teams to repeat the research.

Reviewers are expected to accept only such works for review which they have professional expertise for, and they shall keep confidentiality of the reviewed document. The review shall be objective, constructive, not influenced by the authors' identity or background, or by any commercial issues.

Most pressure is still being put on the editors who should have the highest motivation to publish authentic and high-quality research results. They are responsible for the content of the journal, they assure quality of the content that they publish, and shall make sure all research published has been done in ethical manners. Editors are those who pick reviewers and ensure they are honest and qualified professionals in their research area. Editors should also conduct fair communication with the reviewers and authors, they should respond to all comments and complaints by either side and make all effort to resolve these. Editors shall further ensure intellectual property rights of the authors. They should keep aware of new issues within intellectual property laws and conventions.

By accepting these standards, Geoinformatics FCE CTU joins the large international family of scholarly publishers of high-quality content who have done all they could to guarantee high scientific and technical quality of the published materials.

We wish all readers and editors continuous quality improvement and much success in the future!

Lenka Němečková Iva Adlerová

CTU in Prague - Central Library 